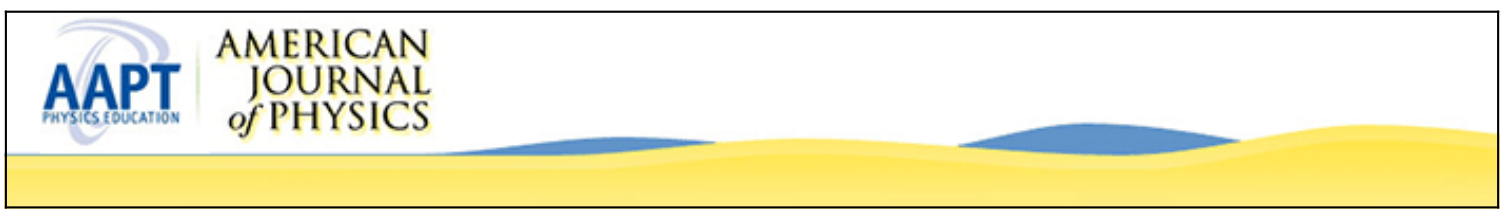

\title{
A versatile digital timer circuit
}

David L. DuPuy

Citation: American Journal of Physics 51, 183 (1983); doi: 10.1119/1.13458

View online: http://dx.doi.org/10.1119/1.13458

View Table of Contents: http://scitation.aip.org/content/aapt/journal/ajp/51/2?ver=pdfcov

Published by the American Association of Physics Teachers

\section{Articles you may be interested in}

An improved spark-timer circuit

Am. J. Phys. 48, 321 (1980); 10.1119/1.12348

The author of the original counter-timer circuit disagrees

Phys. Teach. 15, 557 (1977); 10.1119/1.2339773

Electronic counter-timers for $\$ 6.00$ per digit

Phys. Teach. 15, 54 (1977); 10.1119/1.2339534

A durable, versatile circuit wiring system

Am. J. Phys. 44, 605 (1976); 10.1119/1.10402

Nearest Count Indication in Counter Timers and Related Analog-Digital Converters

Rev. Sci. Instrum. 31, 1241 (1960); 10.1063/1.1716862

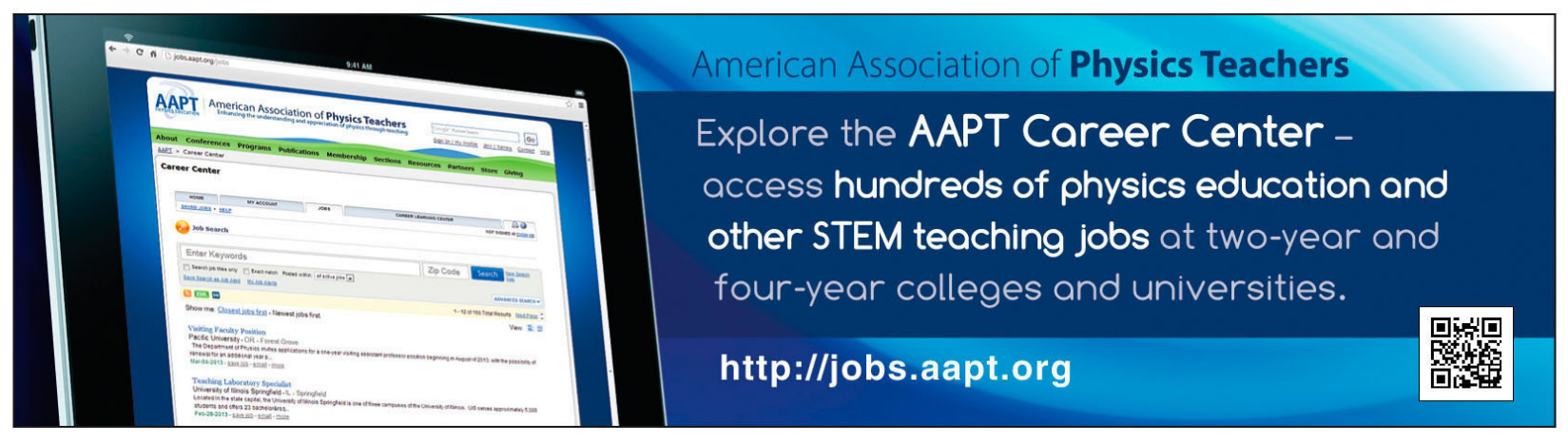




\section{Simple modification of the overhead projector allows vertical formats}

Arvid T. Lonseth

Department of Physics, Southern Oregon State College, Ashland, Oregon 97502

Some demonstrations whose small size merit optical projection cannot be used with a standard overhead projector because they cannot readily be made to lie in a horizontal plane. A delightfully simple modification of the projector was described in passing by $R$. L. Wild in a recent Apparatus Note ${ }^{1}$ : Because the idea is of general use, but might easily have been missed by readers, this note is to emphasize explicitly the method which consists in laying " ...the projector on its back so that the image is formed on the ceiling. Then by taping a small shaving mirror to the lens box of the projector we send the erect image to the front of the classroom." Before using this method you should check to make sure you are not interfering with the cooling system for the bulb.

'R. L. Wild, Am. J. Phys. 49, 1185 (1981).

\section{A versatile digital timer circuit}

David L. DuPuy

Saint Mary's University, Halifax, Nova Scotia B3H 3C3, Canada

\section{INTRODUCTION}

We required a versatile digital timer to operate the shutter on our CCD (charge coupled device) system. It was decided not to buy a commercial timer, and we did not wish to tie up the computer during exposures; hence an inhouse, hard-wired timer was considered. An Intersil CMOS timer chip was selected and simple support logic was wired into the timer circuit. Alas, it was then realized that a little more external logic was required to meet our basic timer requirements. The resulting circuit, although simple, evolved only after some experimentation. It is given here to save development time for others interested in an inexpensive hard-wired timer. The total cost is about $\$ 60$.

The integrated circuit chosen was the Intersil 7217A (Fig. 1; $U 1$ on the diagram), with four digits, up-down counting, on-chip LED drivers, and other features. The A version provides counting to $9999 \mathrm{~s}$ (a 59-min, 59-s version

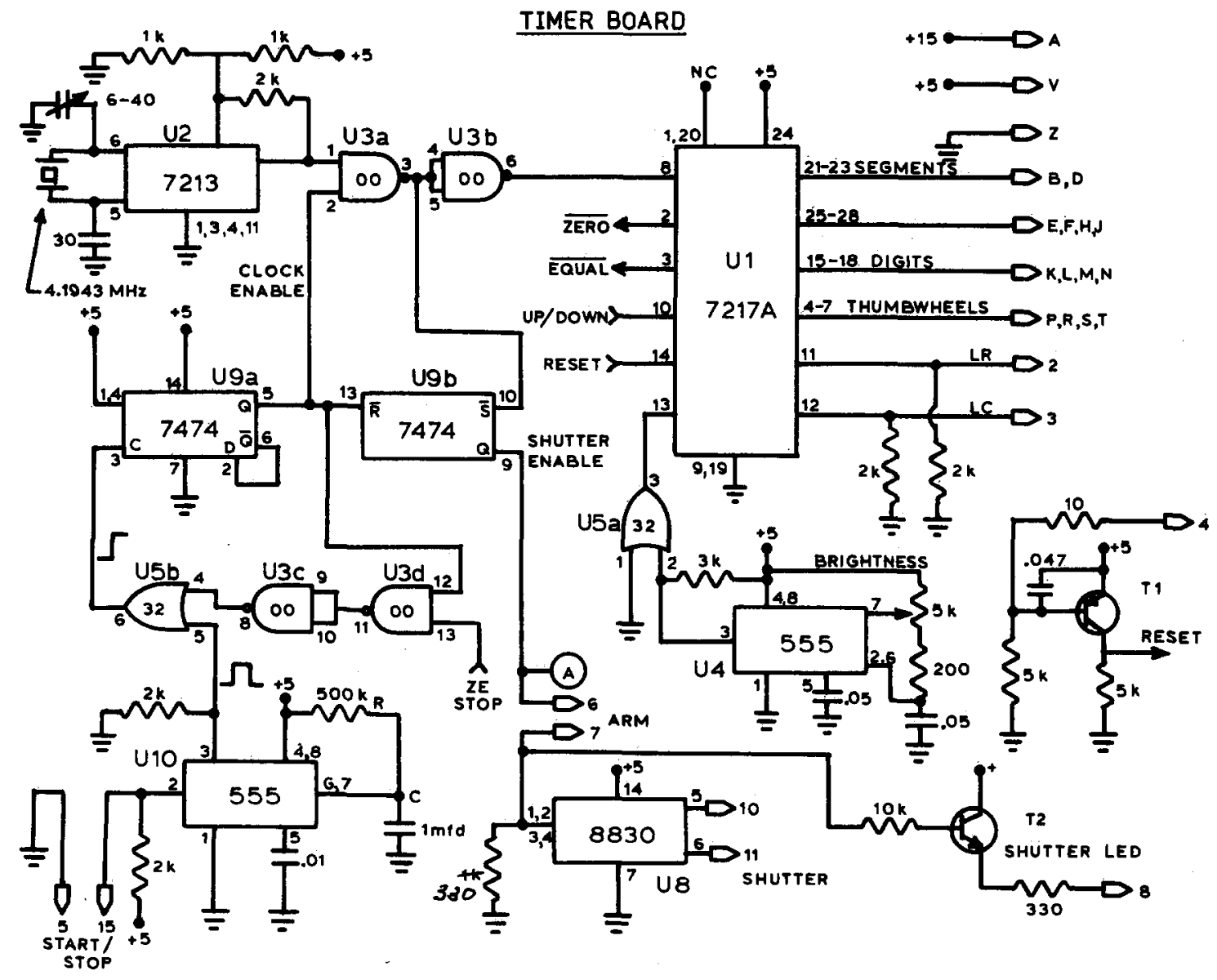

Fig. 1. Basic timer circuit, including the timer chip, the clock start-stop logic, and shutter line driver. 

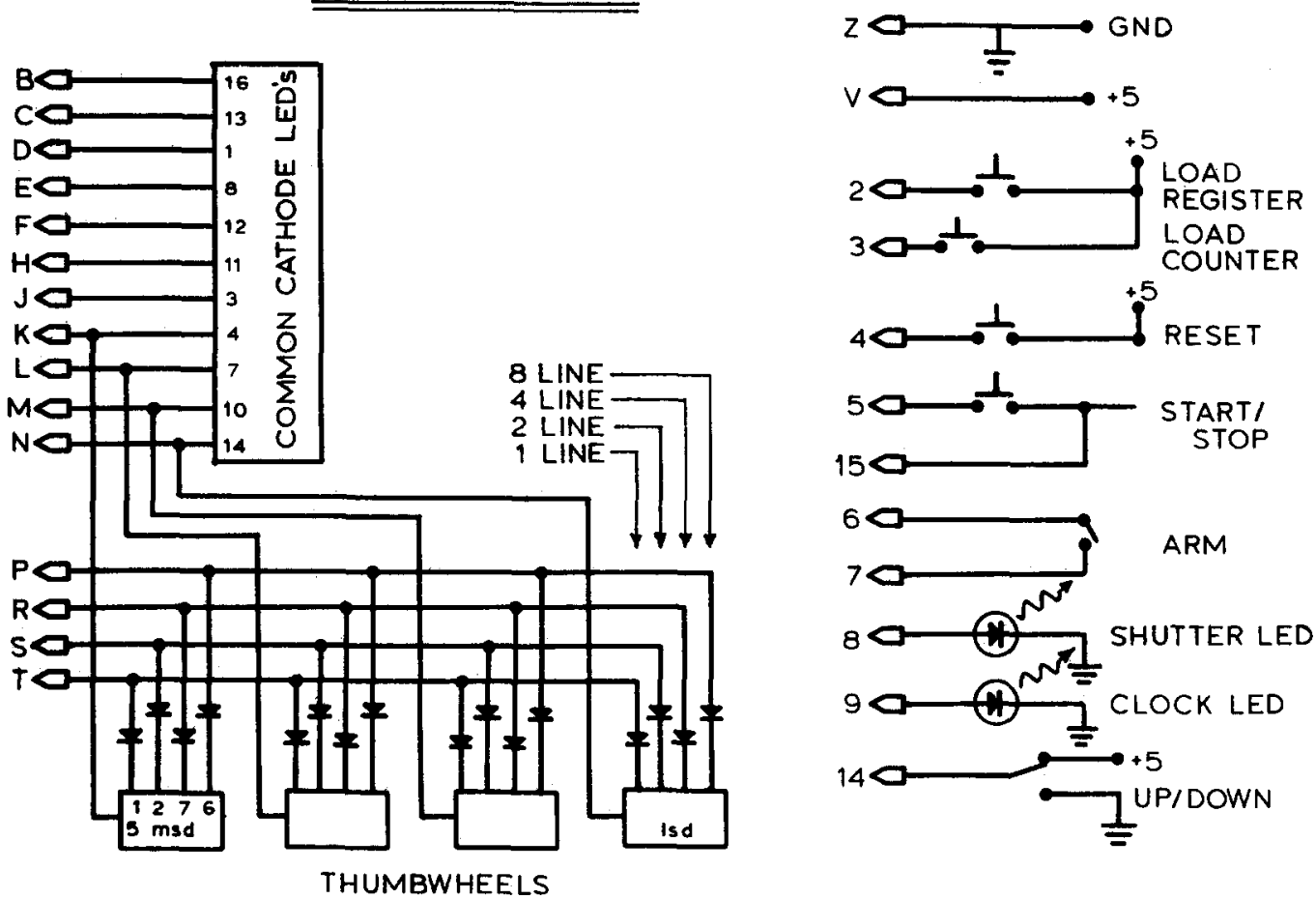

Fig. 2. Front panel wiring for the timer.

is also available) and common cathode LED's (a common anode version is available). Thumbwheel switches (Fig. 2) are used to preset the up counter to a given final count (which produces a signal on the EQUAL pin, Fig. 3), or to load the starting count, for counting down to zero. Both the outputs to the LED readouts and the inputs from the thumbwheel switches are multiplexed.

For normal 1-s counting, a $1-\mathrm{Hz}$ clock signal is input on pin 8 of $U 1$. To produce this, we used an Intersil 7213 integrated circuit $(U 2)$, which has an on-chip crystal oscillator, and divides the signal by $2^{22}$. For $1 \mathrm{~Hz}$, the external crystal is $4.1943 \mathrm{MHz}$. It should be noted that this IC does not operate properly at this frequency on $+5 \mathrm{~V}$. The fine print on the spec sheet was not read carefully enough the first
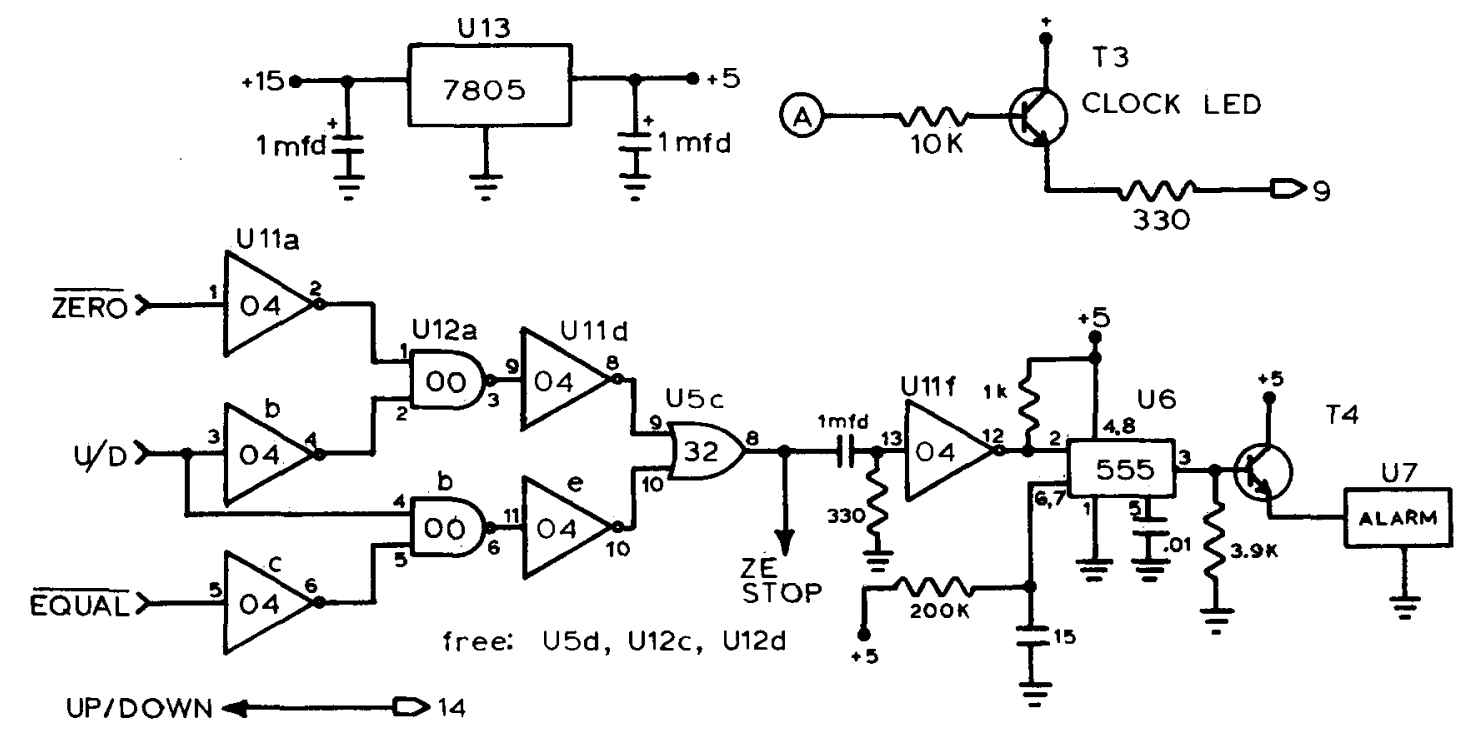

Fig. 3. Stop logic circuit and alarm circuit for the timer. time, and we had problems until the supply voltage to this IC was lowered to $+2.5 \mathrm{~V}$ (as the spec sheet recommends). A simple voltage divider as shown is adequate here, since the supply current is low.

\section{CONSTRUCTION}

The circuit was built on a Vector $3677-2,4 \frac{1}{2} \times 6 \frac{1}{2}$ in. board, which plugged into a socket to be wired to the front panel readout and control switches. The use of wire wrap techniques on a Vector board is probably the easiest route for construction. The circuit shown assumes 8-15 Vdc input to the $+5-\mathrm{V}$ regulator $\mathrm{IC}$, which is the only voltage required. 
Two of the subcircuits shown are taken from the Intersil spec sheet. $U 4$ is an astable multivibrator, which controls the brightness of the display. The circuit involving $T 1$ (transistor 1) insures an orderly reset on powering up.

The primary contribution of this note involves the logic concerned with starting and stopping the clock signal; this uses IC's $U 3, U 5, U 9, U 10, U 11$, and $U 12$. We required that in the count-up mode, a reset to zero (to begin the count) must not activate the buzzer or affect the shutter. This occurred in our first circuit, since the $\overline{\text { ZERO }}$ signal was used directly to trigger the buzzer when counting down. First, the count up-count down switch is set. The counter is then reset, or preset, as required. When the START-STOP button is pressed to start the count, the 555 $(U 10$, wired as a monostable multivibrator) issues a positive pulse roughly $0.5 \mathrm{~s}$ long. This signal is gated through $U 5 b$ to the clock input of $U 9 a$, a 7474 flip-flop. The $Q$ output of $U 9 a$ is set high, and this is the CLOCK ENABLE line. On the next rising clock pulse, the output of $U 3 a$ sets the $Q$ output of $U 9 b$ high, which is the SHUTTER ENABLE line, thus opening the shutter. It is important to note that the shutter is not opened until the first rising clock pulse after the START-STOP button is pushed; if the shutter were opened at once, the shutter would remain open between 0 and $1 \mathrm{~s}$ too long, since the START-STOP button will be pushed at random times with respect to the $1 \mathrm{~Hz}$ clock. Once the clock is running, one of three events will stop the clock and close the shutter:

(1) For a manual halt, the START-STOP button turns off the $U 9 a$ flip-flop, closing the shutter $(U 9 b)$ and stopping the clock $(U 3 a)$. The START-STOP switch can then re- start the clock without resetting the counter in $U 1$.

(2) If COUNT UP is selected, when the count reaches the preset value, the $\overline{\text { EQUAL }}$ signal from $U 1$ is gated through to $U 5 c$, which initiates the ZE STOP SIGNAL. The

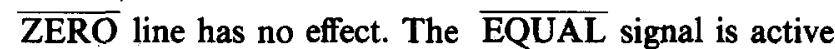
low once the counter reaches (i.e., equals) the preset value.

(3) If COUNT DOWN is selected, the $\overline{\text { ZERO }}$ signal is effective, and stops the clock in a similar manner when the counter reaches zero.

It should be noted that the 555 monostable at $U 10$ for debouncing the START-STOP signal has a time constant of about $0.5 \mathrm{~s}(\sim 1.1 R C)$. Hence this pushbutton must be a momentary contact, not an alternate action switch; $U 9 a$ provides the alternate action. If very short time intervals (less than $1 \mathrm{~s}$ ) are to be timed, two changes must be made. First, of course, the $1-\mathrm{Hz}$ clock signal entering $U 3 a$ would have to be changed to $0.1 \mathrm{~Hz}$ or whatever is appropriate. That would require a different oscillator and divider chain to replace $U$ 2. Second, the START-STOP switch should be replaced with a SET-RESET flip-flop and one pushbutton to START, another for STOP. We chose to avoid that requirement since we have no desire for exposures shorter than $1 \mathrm{~s}$.

Finally, the ZE STOP line triggers $U 6$, which activates an audible buzzer for a few seconds. The green LED indicates that the clock is running (i.e., gated through to the counter chip) and the red LED indicates that the shutter is open. The ARM switch permits experimenting with the counter while leaving the shutter safely closed. Since our shutter was about $20 \mathrm{~m}$ away, we used a line driver $(U 8)$ to activate the shutter circuitry.

\title{
Demonstrations for teaching nuclear energy
}

\author{
Joseph Priest and James Poth \\ Department of Physics, Miami University, Oxford, Ohio 45056
}

It is reasonable to expect students to understand the rudiments of the physics and technology of nuclear energy in view of the current dilemma concerning the commercial use of nuclear power. However, the concepts involved in teaching nuclear energy are often not easily grasped by many students. This difficult teaching task is compounded when a student is one of many in a large classroom. For teachers facing these challenges, we offer some suggestions for nuclear energy demonstrations designed for use on an overhead projector.

\section{RADIOACTIVITY}

The decay of a radioactive nucleus, like calling the correct number on a rolled die, is a chance event. The decays in a sample of radioactive nuclei can be simulated by rolling a number of dice and counting the occurrence of a particular number. To present this demonstration to a class using an overhead projector, a face-centered hole is drilled completely through each die. A hole appearing face up during a roll of the dice signifies a nuclear disintegration. When the dice are rolled on the writing surface of an overhead projector, disintegrations are identified on the viewing screen as spots of light in the centers of the outlines of the dice (Fig. 1). A demonstration starting with 20 dice takes a short time and produces meaningful results. After each roll of the dice, the disintegrations are removed and the number re- maining is plotted versus roll number which is taken as a measure of elapsed time (Fig. 2). The radioactive decay process is simulated nicely, and we can show in principle how a half-life is determined in an actual radioactive decay experiment.

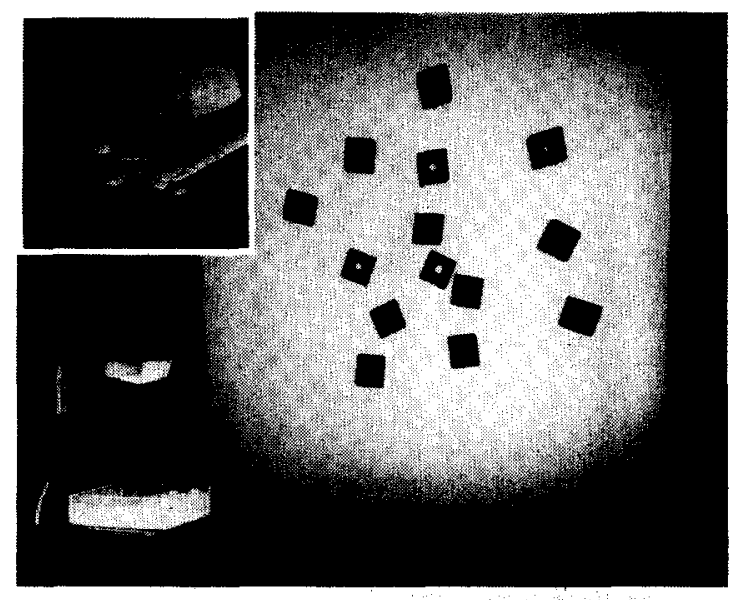

Fig. 1. Radioactive nucleus is modeled with an ordinary die having a facecentered hole drilled completely through the die (insert). When rolled, a hole facing up depicts the decay of a nucleus. The outlines of dice rolled on the writing surface of an overhead projector are projected onto a viewing screen. Those with a central white spot depict nuclear disintegrations. 